\title{
Cellular Changes Resembling Foveolar Epithelium Cells
}

National Cancer Institute

\section{Source}

National Cancer Institute. Cellular Changes Resembling Foveolar Epithelium Cells. NCI Thesaurus. Code C95509.

A morphologic finding indicating the presence of cells that resemble gastric foveolar epithelial cells. 